\title{
Hydrogen Accelerated Fatigue Crack Growth of Friction Stir Welded X52 Steel Pipe
}

\author{
J.A. Ronevich ${ }^{1}$, B.P. Somerday ${ }^{2}$, Z. Feng ${ }^{3}$ \\ ${ }^{1}$ Sandia National Laboratories, Livermore, CA, 94550, USA \\ ${ }^{2}$ Southwest Research Institute, San Antonio, TX, 28510, USA \\ ${ }^{3}$ Oak Ridge National Laboratory, Oak Ridge, TN 37831, USA
}

\begin{abstract}
Friction stir welded steel pipelines were tested in high pressure hydrogen gas to examine the effects of hydrogen accelerated fatigue crack growth. Fatigue crack growth rate (da/dN) vs. stress-intensity factor range $(\Delta \mathrm{K})$ relationships were measured for an X52 friction stir welded pipe tested in $21 \mathrm{MPa}$ hydrogen gas at a frequency of $1 \mathrm{~Hz}$ and $\mathrm{R}=0.5$. Tests were performed on three regions: base metal (BM), center of friction stir weld (FSW), and $15 \mathrm{~mm}$ off-center of the weld. For all three material regions, tests in hydrogen exhibited accelerated fatigue crack growth rates that exceeded an order of magnitude compared to companion tests in air. Among tests in hydrogen, fatigue crack growth rates were modestly higher in the FSW than the BM and $15 \mathrm{~mm}$ off-center tests. Select regions of the fracture surfaces associated with specified $\Delta \mathrm{K}$ levels were examined which revealed intergranular fracture in the BM and $15 \mathrm{~mm}$ off-center specimens but an absence of intergranular features in the FSW specimens. The X52 friction stir weld and base metal tested in hydrogen exhibited fatigue crack growth rate relationships that are comparable to those for conventional arc welded steel pipeline of similar strength found in the literature.
\end{abstract}

Keywords: Hydrogen embrittlement; friction stir weld; hydrogen assisted cracking; fatigue crack growth rate

\section{Introduction}

Hydrogen fuel delivery over long range distances from production facilities to fueling stations requires a cost effective means of hydrogen transportation. Steel pipelines represent the most economical means to develop an infrastructure necessary to meet the anticipated demand with the emergence of fuel cell vehicles. Steel hydrogen pipelines have been safely operated in North America and Europe for decades through thousands of kilometers of pipe for industrial gas suppliers and oil refineries [1]. However, current hydrogen pipelines are typically operated at constant, relatively modest pressures due to the consistent demand. With an influx of fuel cell vehicles, hydrogen demand will increase and it will be necessary to expand the operating envelope to higher pressures. Furthermore, the pipe will sustain more frequent pressure fluctuations resulting from variation in production and demand.

Steel hydrogen pipelines subjected to cyclic pressure (wall stress) are susceptible to a subcritical cracking mode referred to as hydrogen accelerated fatigue crack growth (HA-FCG). In hydrogen, fatigue crack growth rates accelerate to rates over an order of magnitude greater than samples tested in air [2-7]. The effects of hydrogen accelerated fatigue crack growth have been evaluated 
on pipeline base metals [2-7]; however recently, a few studies [8-10] have emerged on weld behavior. Welds represent an area of concern as varied microstructures could result in increased susceptibility to HA-FCG. The focus of the studies performed [8-10] has been on evaluating the performance of conventional gas metal arc welds as compared to their respective base metal. In general, only modest increases in HA-FCG were observed in the arc welds compared to the base metal [8-10].

Advanced joining processes such as friction stir welding (FSW) provide an alternative means of constructing steel pipelines as compared to the conventional arc welding processes [11]. FSW is a process that requires no consumables or shielding gas because it involves no melting of metal. This results in a reduction of pipeline installation costs [12]. A solid-state weld is fabricated by inserting a non-consumable welding tool into the steel at the mating surfaces and mechanically mixing the metal to form a permanent joint. Heat input is lower than conventional consumable welding which prevents solidification cracking, reduces the size of the heat affected zone, and reduces the magnitude of residual stresses [11]. Friction stir welding capabilities are not yet deployable in the field for pipelines; however, recent [12] advances in research suggests this technique will become feasible in the near future. Although FSW presents a lower cost alternative to conventional arc welding techniques, the susceptibility of FSW to hydrogen assisted fatigue crack growth has not been evaluated.

The goal of this work is to measure fatigue crack growth rates of a friction stir welded X52 steel pipe in $21 \mathrm{MPa}$ high pressure hydrogen gas and compare to conventional arc welding data in the literature. Three regions of the welded pipe were examined: base metal, center of weld, and 15 $\mathrm{mm}$ off-center to weld. The FCGR were slightly higher in the weld compared to the base metal and off-center region in hydrogen gas. The HA-FCG rates were comparable between friction stir welds and conventional arc welds of similar grade pipeline steels reported in the literature.

\section{Experimental Procedures}

A friction stir welded X52 steel pipe with an outer diameter of approximately $340 \mathrm{~mm}$ (13.4 in) and a nominal wall thickness of $6.35 \mathrm{~mm}$ ( $0.25 \mathrm{in})$ was investigated in this study. The chemical composition of the base metal, shown in Table 1, was measured at an outside lab ${ }^{1}$. The pipe contained a friction stir weld in the circumferential direction (e.g. girth weld) as shown in Figure 1a. A poly crystalline boron nitride ( $\mathrm{PCBN})$ tool was used for welding which was performed under load control with a plunge load of $67 \mathrm{kN}(15,000 \mathrm{lbf})$ and welding speed of $102 \mathrm{~mm} / \mathrm{min}$ (4 in/min). The orientation directions of the welded pipe are referred to as longitudinal (L), circumferential (C), and radial (R), as indicated in Fig. 1a.

Eccentrically loaded single edge notched tension $(\operatorname{ESE}(T))$ specimens were machined from the welded pipe according to ASTM E647-11 [13]. Figure 1b is a schematic showing the 3 locations of the specimen extractions, labeled as base metal (BM), friction stir weld (FSW), and $15 \mathrm{~mm}$

| ${ }^{1}$ Anamet Inc. by Spectrochemical Analysis 
off-center from the weld. All specimens were oriented such that the load was applied in the longitudinal direction and the crack extended in the circumferential direction.

Light optical microscopy was performed on the FSW and is shown in the etched condition in Fig. 1c. The stirred zone appears darker than the base metal. The dashed blue and red lines represent the approximate locations of the crack planes for the FSW and off-center specimens, respectively. In Fig. 1c, the crack growth direction would be normal to the page. The $15 \mathrm{~mm}$ offcenter location was chosen to evaluate the adjacent base metal that may be affected due to the welding process (i.e. thermal history). The specimens were extracted on the advancing side of the weld as shown in Fig. 1c. The location represented by the dashed red line in Fig. 1c was sufficiently offset from the weld such that the entire crack plane was located within a uniform microstructure. This location permitted unambiguous interpretation of the fatigue crack growth rate data compared to a specimen with half of the crack plane located in the FSW and half in the BM.

Metallographic sections of the three different material regions were examined in a scanning electron microscope (SEM). Figures 2a, 2b, and 2c show the SEM images of the BM, $15 \mathrm{~mm}$ off-center, and FSW, respectively. The microstructure of the BM as shown in Fig. 2a is predominantly polygonal ferrite with pearlite colonies. The microstructure of the $15 \mathrm{~mm}$ offcenter, shown in Fig. 2b, consists of ferrite and pearlite similar to the BM but also contains a small fraction of carbides dispersed in the ferrite. Negligible grain growth was observed in the 15 $\mathrm{mm}$ off-center region as compared to the BM. The microstructures do not vary significantly between the BM and the $15 \mathrm{~mm}$ off-center regions. Figure $2 \mathrm{c}$ reveals the microstructure of the FSW as predominantly carbides in ferrite, where the ferrite grain size appears refined compared to the BM, and the amount of pearlite was significantly less in the FSW microstructure as compared to the BM.

Vickers microhardness was measured across the friction stir weld and base metal as shown in Fig. 3. Measurements were taken at the mid-thickness position at $0.5 \mathrm{~mm}$ increments using a 500-gram load. The blue and red dashed lines on the micrograph in Fig. 3 show the approximate locations of the crack plane of the FSW and $15 \mathrm{~mm}$ off center specimens, respectively. The average Vickers hardness was $174 \mathrm{VH}$ across the entire weld. Vickers hardness values between 170 and 180 were measured at the BM, FSW, and $15 \mathrm{~mm}$ off-center locations corresponding to specimen extraction. Overall, microhardness values were similar among all material regions tested.

Table 1 - Chemical Composition of X52 Base Metal

\begin{tabular}{|c|c|c|c|c|c|c|c|c|c|c|c|c|c|}
\hline $\mathbf{C}$ & $\mathbf{M n}$ & $\mathbf{P}$ & $\mathbf{S}$ & $\mathbf{S i}$ & $\mathbf{C u}$ & $\mathbf{N i}$ & $\mathbf{C r}$ & $\mathbf{M o}$ & $\mathbf{V}$ & $\mathbf{T i}$ & $\mathbf{N b}$ & $\mathbf{A l}$ & $\mathbf{F e}$ \\
\hline 0.054 & 1.02 & 0.009 & $<0.005$ & 0.16 & 0.08 & 0.03 & 0.03 & 0.01 & $<0.005$ & $<0.005$ & 0.02 & 0.03 & Bal. \\
\hline
\end{tabular}

$\operatorname{ESE}(\mathrm{T})$ specimens were designed with a width $(\mathrm{W})=19 \mathrm{~mm}$, thickness $(\mathrm{B})=4.76 \mathrm{~mm}$, and precrack starter notch length-to-width ratio $(\mathrm{a} / \mathrm{W})=0.2$. Prior to precracking, specimens were 
ultrasonically cleaned in ethanol. Precracking was performed in air under the following conditions: load-cycle frequency $=15 \mathrm{~Hz}$, final maximum stress intensity factor $\left(\mathrm{K}_{\max }\right)=13.2$ $\mathrm{MPa} \mathrm{m}^{1 / 2}$, and R-ratio $\left(\mathrm{K}_{\min } / \mathrm{K}_{\max }\right)=0.5$. Final precrack lengths $(\mathrm{a} / \mathrm{W})$ ranged from 0.28 to 0.31 .

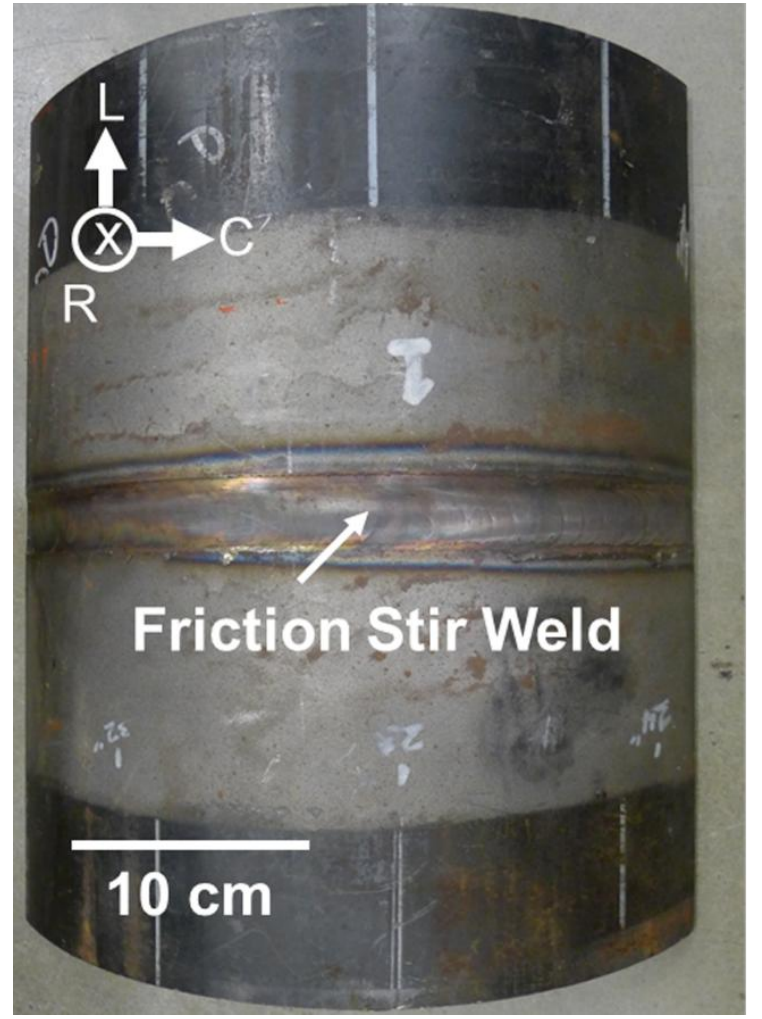

(a)

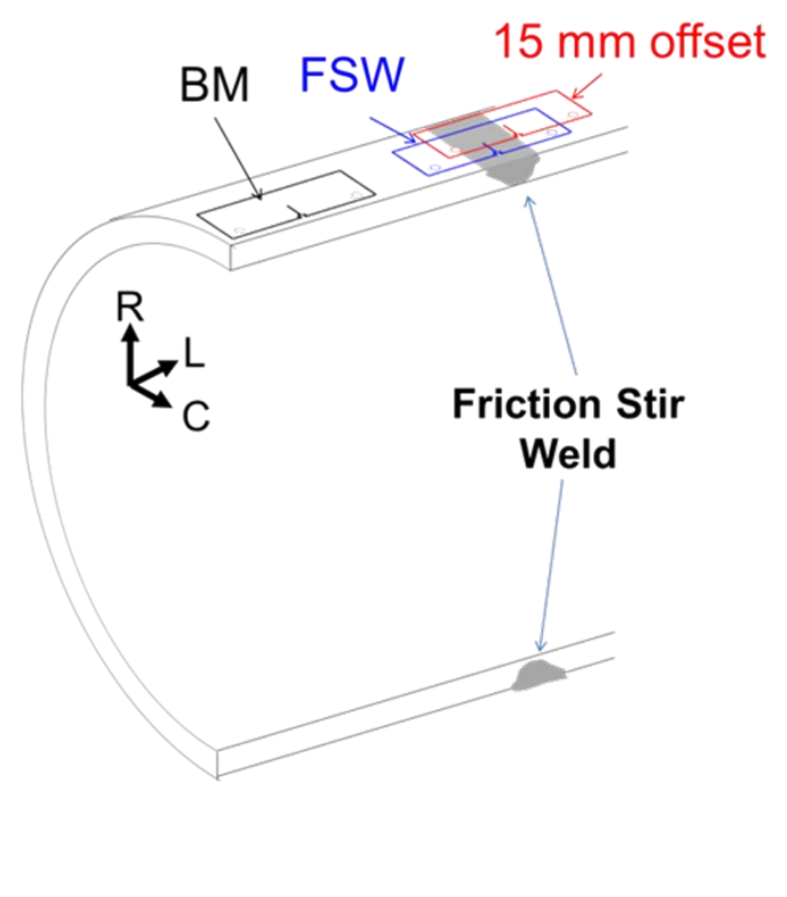

(b)

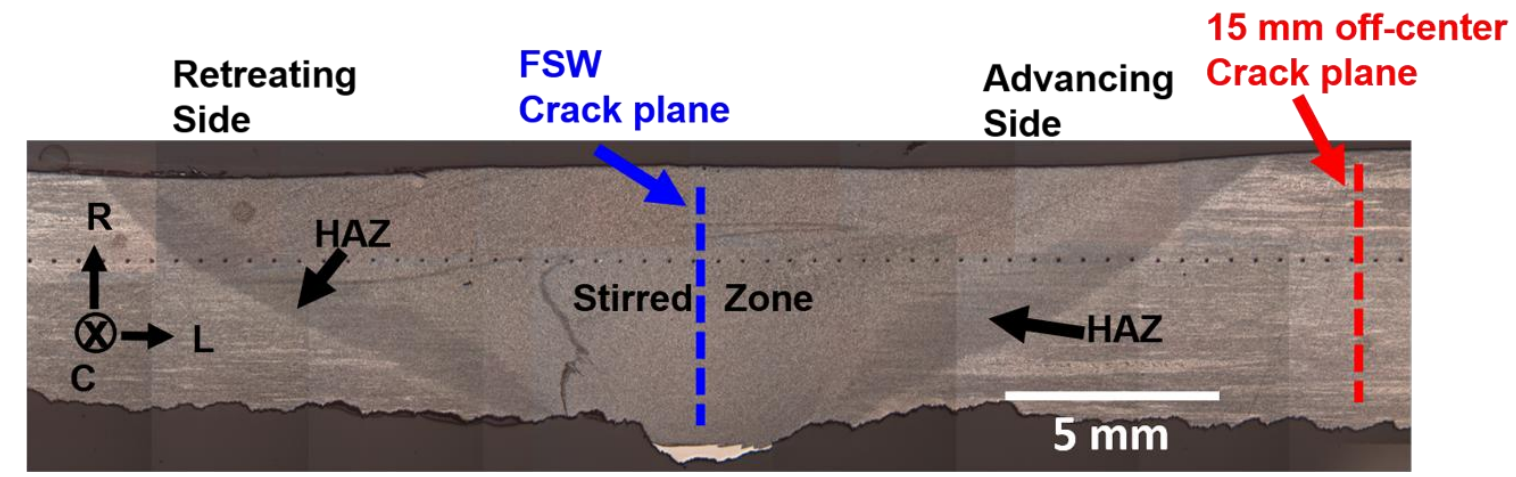

(c)

Figure 1 (a) Image of X52 friction stir girth welded pipe. The friction stir weld tracks in the circumferential direction, (b) schematic of $\operatorname{ESE}(\mathrm{T})$ specimen orientations relative to the pipe, (c) macrograph of etched friction stir weld region. Dashed blue and red lines represent the approximate crack plane locations of the FSW and $15 \mathrm{~mm}$ 
off-center specimens, respectively. Crack propagation would be into the page as shown in (c).

Fatigue crack growth testing was performed on ESE(T) specimens in high-purity (99.9999\%) hydrogen gas at room temperature $(295 \mathrm{~K})$. Specimens were inserted into a servo-hydraulic load frame integrated with a custom built pressure vessel that permits mechanical loading and hydrogen gas exposure. The pressure vessel is equipped with spring energized Teflon ${ }^{\circledR} \mathrm{U}$-cup seals which prevent gas leaks between the bottom cover bore and pull rod while allowing dynamic pull rod motion. After assembly of the pressure vessel, residual air was removed from the gas chamber through 4 successive purges with high purity helium (13.8 MPa) followed by vacuum. Four successive purges with high purity hydrogen gas (13.8 MPa) were applied prior to final filling to the test pressure. The test pressure was selected at $21 \mathrm{MPa}$ hydrogen gas as this is identified as an upper bound for future hydrogen pipelines in the ASME B31.12 code "Hydrogen Piping and Pipelines" [14]. The pressure vessel assembly with ESE(T) specimen is maintained at a pressure of $21 \mathrm{MPa}$ to permit the strain gauge-based load cell and extensometer to equilibrate before initiating the test; strain gauges can experience signal drift during initial exposure to high pressure hydrogen gas. Specimens did not sustain mechanical loads during filling with high pressure gas due to a balance chamber in the pressure vessel that ensures the pull rod is subjected to an equal and opposite force.

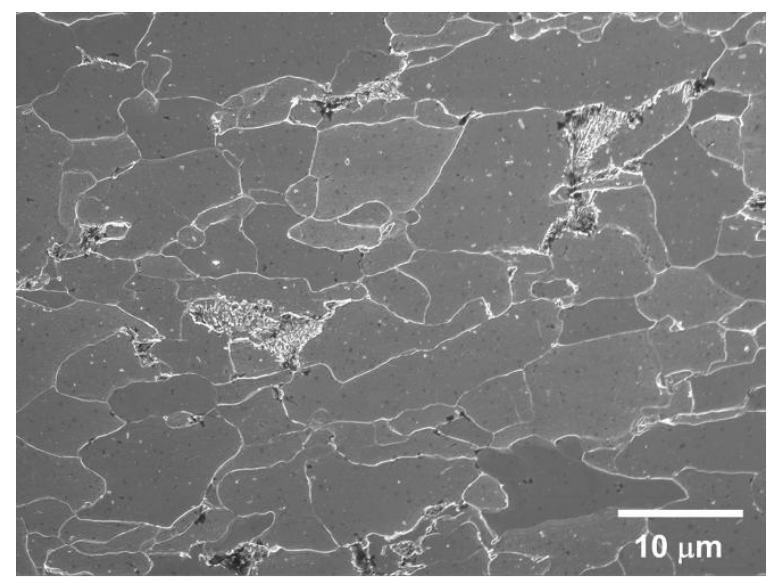

(a)

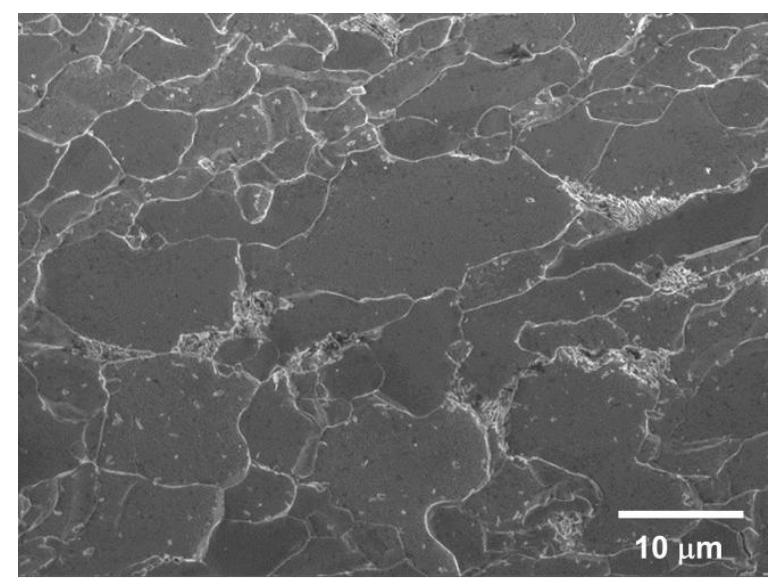

(b) 


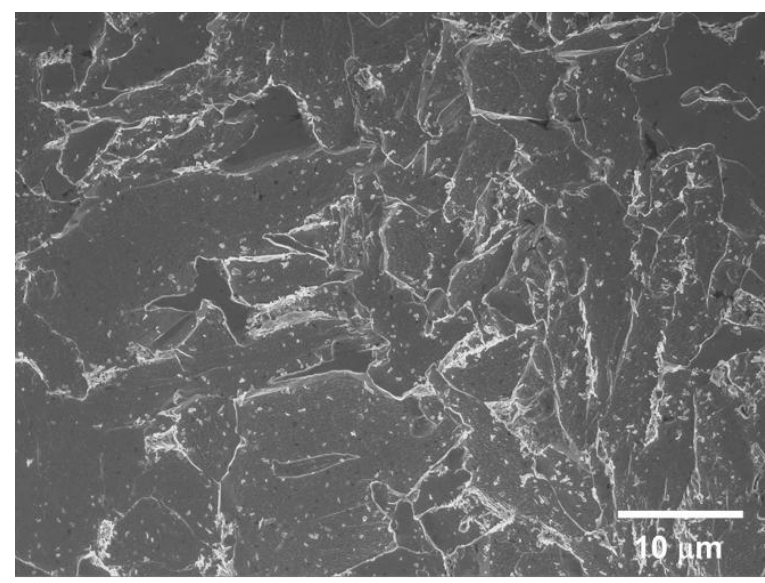

(c)

Figure 2 Scanning electron microscope images of (a) BM, (b) $15 \mathrm{~mm}$ off-center, and (c) center of friction stir weld. $2 \%$ nital etch. Images are of the radial-longitudinal plane.

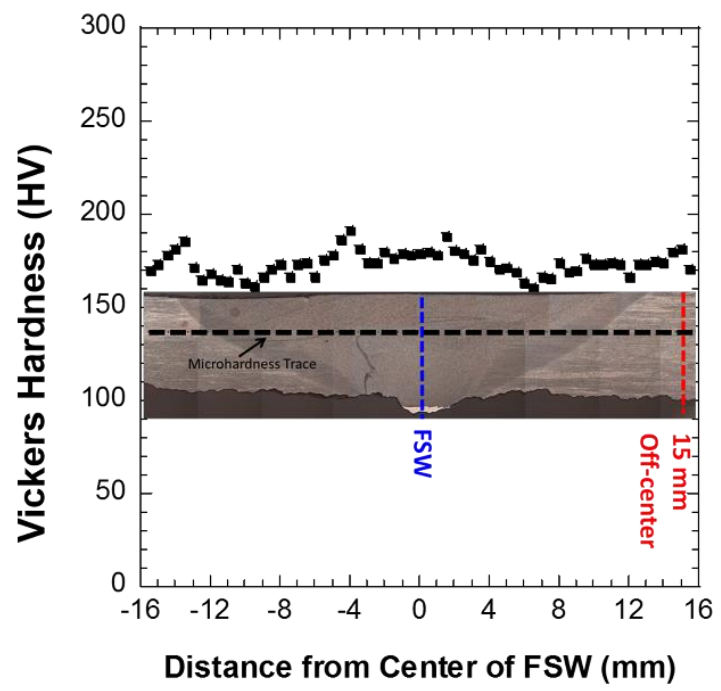

Figure 3 Vickers microhardness trace across friction stir weld and base metal. Optical image of weld is overlaid to show approximate location of indents.

Fatigue testing was performed under constant load amplitude conditions in high pressure hydrogen gas at a frequency of $1 \mathrm{~Hz}$ and a load ratio of $\mathrm{R}=0.5$. In this loading format, the load amplitude is constant and the stress intensity factor range $(\Delta \mathrm{K})$ increases as the crack grows. Fatigue crack growth rates for pipeline steels in hydrogen gas can be sensitive to test frequency with higher crack growth rates at lower frequencies [3, 5]; however, testing at low frequencies requires an excessive amount of time. Therefore, selection of the test frequency at $1 \mathrm{~Hz}$ was a balance between testing efficiency and measuring upper bound crack growth rates. A triangular waveform was applied and loads were cycled between set minimum and maximum values. An internal load cell was used to provide feedback in the control loop, which ensured that the loads 
experienced by the specimen did not include friction forces from the U-cup seals. The crack mouth opening displacement was monitored using a strain gauge-based extensometer. Crack length was calculated from the unloading compliance technique. Load, crack opening displacement, and crack length were digitally recorded every $0.1 \mathrm{~mm}$ of crack extension.

A seven-point incremental polynomial method [13] was used to calculate crack growth increment per load cycle, da/dN, as function of stress intensity factor range, $\Delta \mathrm{K}$. After removal from the pressure vessel, specimens were soaked in liquid nitrogen for a minimum of 10 minutes and then fractured open. Three distinct regions of crack extension were observed on the fracture surface: precrack in air, crack extension in hydrogen, and fracture in liquid nitrogen. The initial and final crack lengths were optically measured to serve as corrections to crack lengths calculated from unloading compliance. The initial and final crack lengths measured optically were set as fixed bounds to linearly correct the intermediate crack lengths determined from the unloading compliance method. Optically measured crack lengths were typically within $20 \%$ of the initial compliance-calculated value and within $2 \%$ of the final calculated value.

Following completion of select tests, gas samples were collected and analyzed by a commercial laboratory for oxygen containing species, which can inhibit hydrogen assisted fatigue crack growth [5]. Impurity contents of the gas samples did not exceed $1 \mathrm{vppm} \mathrm{O}_{2}$ and $29 \mathrm{vppm} \mathrm{H}_{2} \mathrm{O}$ and are therefore not expected to significantly affect the results in this study.

For comparison, a single test was performed of the base metal in air. All other test parameters were identical to those in hydrogen gas except the load-cycle frequency was increased to $10 \mathrm{~Hz}$. Relative humidity for tests in air was between 30 and 50\%. In order to delineate the different fracture surface regions for the tests in air, specimens were heat tinted at $275^{\circ} \mathrm{C}$ for 30 minutes, soaked in liquid nitrogen, and fractured open.

\section{Results}

Fatigue crack growth relationships (da/dN vs $\Delta \mathrm{K}$ ) were measured for X52 pipeline steel in 21 $\mathrm{MPa}$ hydrogen gas at a frequency of $1 \mathrm{~Hz}$ and $\mathrm{R}$-ratio of 0.5 . Three regions of the pipe were tested: base metal (BM), center of friction stir weld (FSW), and $15 \mathrm{~mm}$ off-center to the weld. The results of triplicate tests performed in hydrogen gas for each material region are shown in Fig. 4 along with a result for base metal tested in air at $10 \mathrm{~Hz}$. Fatigue behavior for the base metal in air shows typical trends of increasing crack growth rate, da/dN, with increasing stress intensity factor range, $\Delta \mathrm{K}$. Specimens tested in hydrogen exhibit accelerated fatigue crack growth, represented by crack growth rates accelerating to more than 40 times greater than rates in air for $\Delta \mathrm{K}>15 \mathrm{MPa} \mathrm{m}^{1 / 2}$. The onset of HA-FCG occurs at low $\Delta \mathrm{K}$ values (e.g. $6-8 \mathrm{MPa} \mathrm{m}^{1 / 2}$, if the data is extrapolated to the curves in air). This trend is observed for all three regions of the pipe tested. The results from triplicate tests in hydrogen are notable for their repeatability. The 
overall fatigue crack growth rate trends observed (e.g. absolute da/dN values and two-slope behavior) in this X52 FSW and base metal pipe are characteristic of ferritic pipeline steels tested previously in hydrogen gas and air [2-8, 10].

A closer look at the FCGRs of the three regions tested reveals differences in behavior, particularly at the low and intermediate stress intensity factor range (e.g. $\Delta \mathrm{K}$ ). At $\Delta \mathrm{K}$ values less than $15 \mathrm{MPa} \mathrm{m}{ }^{1 / 2}$, modest differences in fatigue crack growth rates were observed between the FSW, base metal, and $15 \mathrm{~mm}$ off-center location. The $15 \mathrm{~mm}$ off-center specimens exhibited slightly lower crack growth rates than the base metal at $\Delta \mathrm{K}<15 \mathrm{MPa} \mathrm{m}^{1 / 2}$. In contrast, crack growth rates in the FSW specimens were slightly higher in the $\Delta \mathrm{K}$ range from 10 to $15 \mathrm{MPa} \mathrm{m}^{1 / 2}$ as compared to the BM. Differences in microstructure may contribute to the higher FCGRs in the FSW as compared to the base metal. In order to better characterize the three regions of the X52 pipe and weld, scanning electron microscopy was performed to examine the microstructure and fracture surfaces of select specimens.

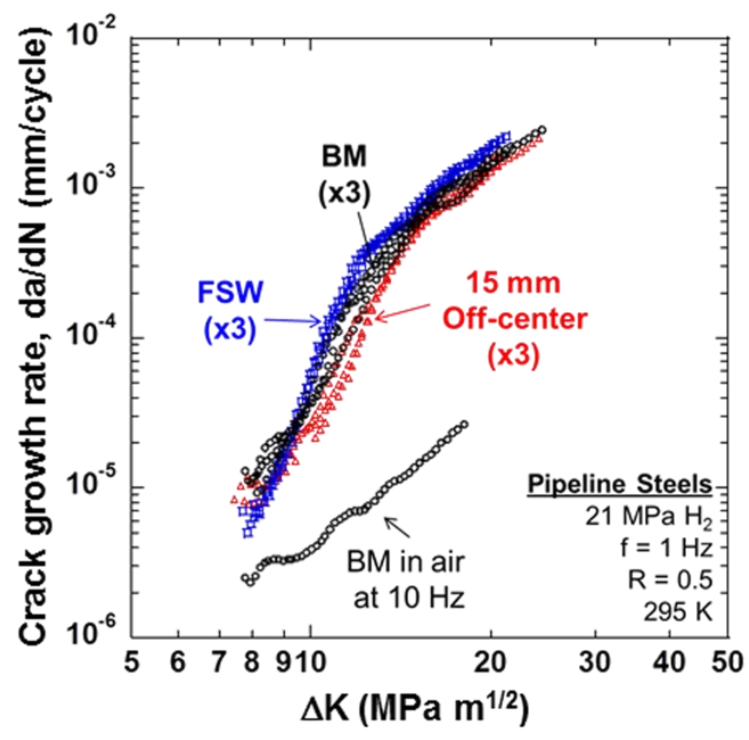

Figure $4 \quad$ Fatigue crack growth relationships (da/dN vs $\Delta \mathrm{K}$ ) for X52 steel pipe tested in 21 MPa hydrogen gas at $1 \mathrm{~Hz}$. Specimens were tested in three locations: base metal (BM), center of friction stir weld (FSW), and approximately $15 \mathrm{~mm}$ off-center from the weld. The $\mathrm{da} / \mathrm{dN}$ vs $\Delta \mathrm{K}$ relationship measured for the BM in air is included for comparison.

Fracture surfaces from select tested specimens were examined to identify prevalent features. Figure 5 shows the optical images of fracture surfaces for the three different regions tested in this study: BM, FSW, and $15 \mathrm{~mm}$ off-center. Distinct regions are labeled on the BM fracture surface: fatigue precrack (air), fatigue in $\mathrm{H}_{2}$, and overload fracture. In all specimens the crack fronts were fairly uniform. Locations on the fracture surfaces were imaged using a scanning electron 
microscope that correspond to specific $\Delta \mathrm{K}$ values for each region of the welded pipe. Figures $6 \mathrm{a}$ and $6 \mathrm{~b}$ show the fracture surfaces of the base metal tested in air at locations of the fracture surface corresponding to $\Delta \mathrm{K} \sim 8.5$ and $15 \mathrm{MPa} \mathrm{m}^{1 / 2}$, respectively. The surface features appear similar between the two images in Figure 6, in which transgranular fracture is the dominant feature.

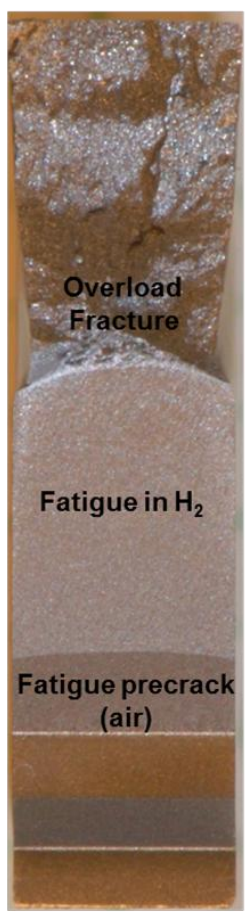

BM

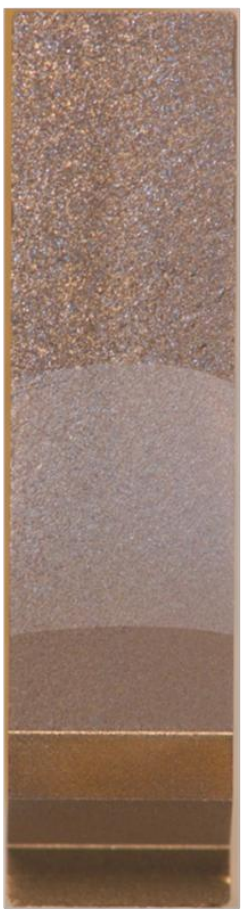

FSW

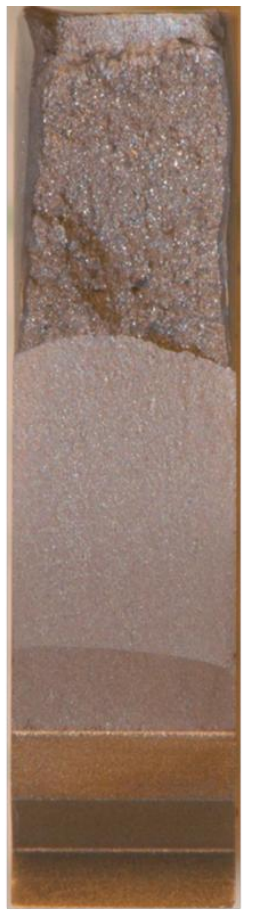

$15 \mathrm{~mm}$

Off-center

Figure 5 Light optical images of BM, FSW, and $15 \mathrm{~mm}$ off-center fracture surfaces. The distinct regions are labeled on the BM surface as fatigue precrack (air), fatigue in $\mathrm{H}_{2}$, and overload fracture following a liquid nitrogen soak. Overall, uniform crack fronts were observed.

Fracture surfaces of specimens tested in $21 \mathrm{MPa}$ hydrogen gas were imaged to determine the features prevalent at different ranges of $\Delta \mathrm{K}$. Figures $7 \mathrm{a}, 7 \mathrm{~b}$, and $7 \mathrm{c}$ show the fracture surfaces of the base metal, $15 \mathrm{~mm}$ off-center, and friction stir weld regions, respectively, at a location on the fracture surface corresponding to $\Delta \mathrm{K} \sim 8.5 \mathrm{MPa} \mathrm{m}^{1 / 2}$ for tests in $21 \mathrm{MPa}$ hydrogen gas. The base metal (Fig. 7a) and off-center (Fig. 7b) fracture surfaces reveal intergranular facets amounting to $20-30 \%$ of the surface area which is consistent with other studies of ferritic pipeline steels tested in hydrogen $[4,5,7]$. White arrows were placed on the images to indicate locations of triple points which is indicative of intergranular fracture. The appearance of intergranular fracture appears to be linked with the onset of hydrogen accelerated fatigue crack growth. 
However, negligible $(<5 \%)$ intergranular facets were observed on the FSW fracture surfaces (Fig. 7c) at a location corresponding to $\Delta \mathrm{K} \sim 8.5 \mathrm{MPa} \mathrm{m}^{1 / 2}$. The crack growth rates in all three regions at $\Delta \mathrm{K} \sim 8.5 \mathrm{MPa} \mathrm{m}^{1 / 2}$ also appear to be similar according to Fig. 4 . Figure 7 shows the fracture surface features at a location corresponding to $\Delta \mathrm{K} \sim 10.5 \mathrm{MPa} \mathrm{m}^{1 / 2}$. The images reveal similar features to those observed at $\Delta \mathrm{K} \sim 8.5 \mathrm{MPa} \mathrm{m}{ }^{1 / 2}$; intergranular and transgranular features are observed on the BM and $15 \mathrm{~mm}$ off-center specimens, whereas negligible intergranular features are observed on the FSW specimen as shown in Figs. 8a, 8b, and 8c, respectively. However, the FCGR at $\Delta \mathrm{K} \sim 10.5 \mathrm{MPa} \mathrm{m}^{1 / 2}$ is $2-3$ times greater in the FSW than the base metal or $15 \mathrm{~mm}$ off-center specimens yet the fracture surfaces exhibit similar features compared to those at $\Delta \mathrm{K} \sim 8.5 \mathrm{MPa} \mathrm{m}^{1 / 2}$. The fracture surfaces of the three regions of the pipe at $\Delta \mathrm{K} \sim 15$ MPa $\mathrm{m}^{1 / 2}$ are shown in Figs. 9a, 9b, and 9c for the BM, $15 \mathrm{~mm}$ off-center, and FSW, respectively. At $15 \mathrm{MPa} \mathrm{m}^{1 / 2}$ and higher, the fracture surfaces of the three regions examined appear similar and consist of predominantly transgranular features. The appearance of similar fracture surfaces is accompanied by the convergence of all da/dN vs $\Delta \mathrm{K}$ curves for $\Delta \mathrm{K}>15$ $\mathrm{MPa} \mathrm{m}^{1 / 2}$ (Fig. 4).

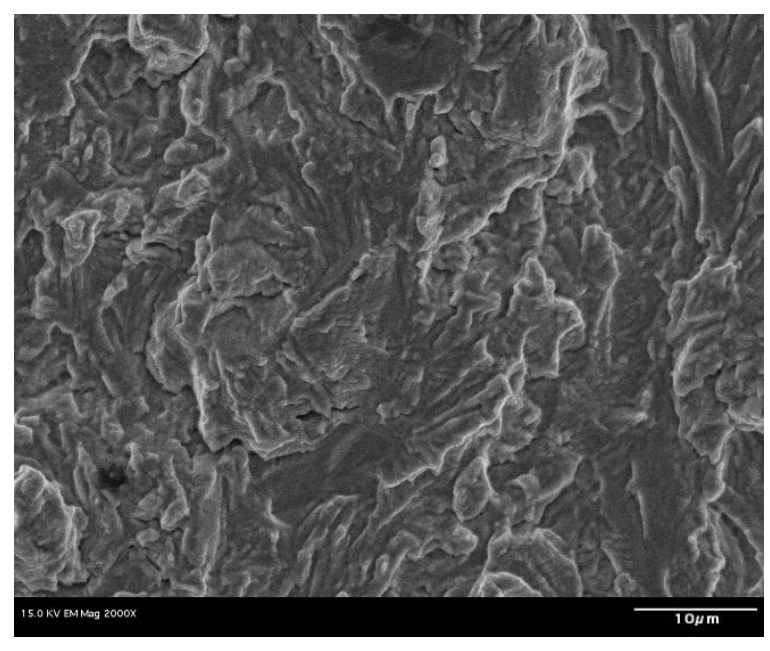

(a)

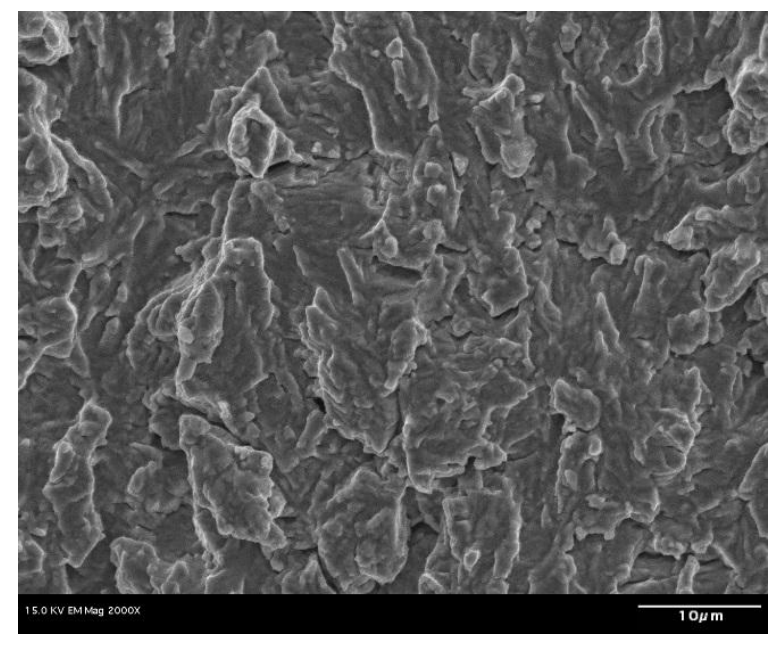

(b)

Figure 6 Scanning electron microscope images of fracture surfaces from fatigue crack growth tests performed in air at $10 \mathrm{~Hz}$ at (a) $\Delta \mathrm{K} \sim 8.5 \mathrm{MPa} \mathrm{m}^{1 / 2}$ and (b) $\Delta \mathrm{K} \sim 15 \mathrm{MPa} \mathrm{m}^{1 / 2}$. In both images, crack growth direction is from bottom to top. 


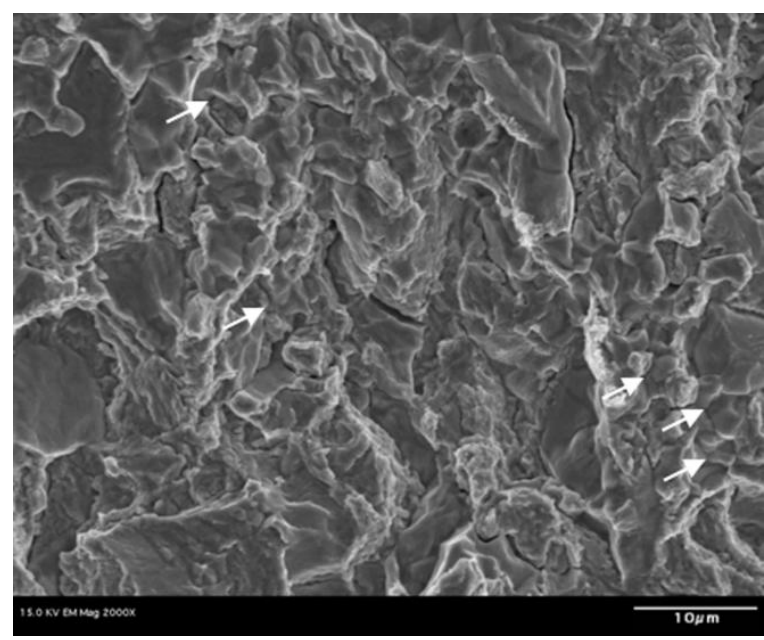

(a)

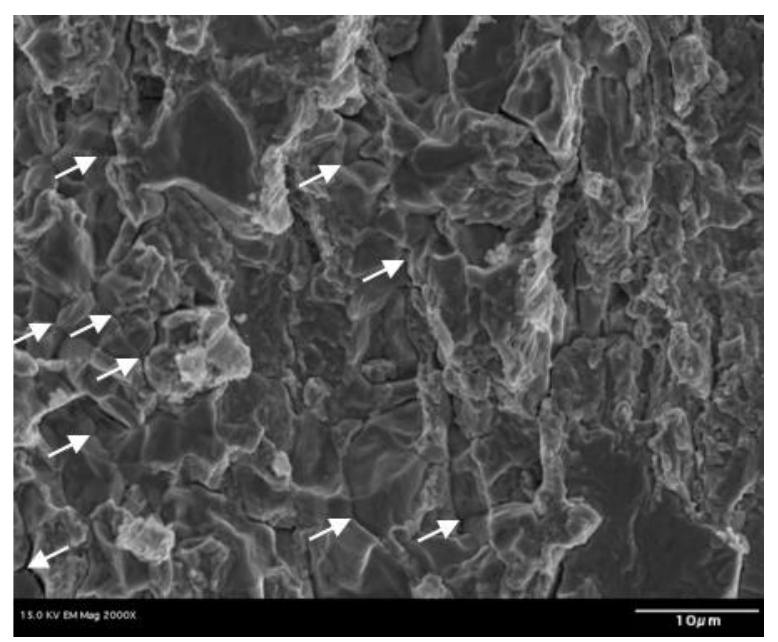

(b)

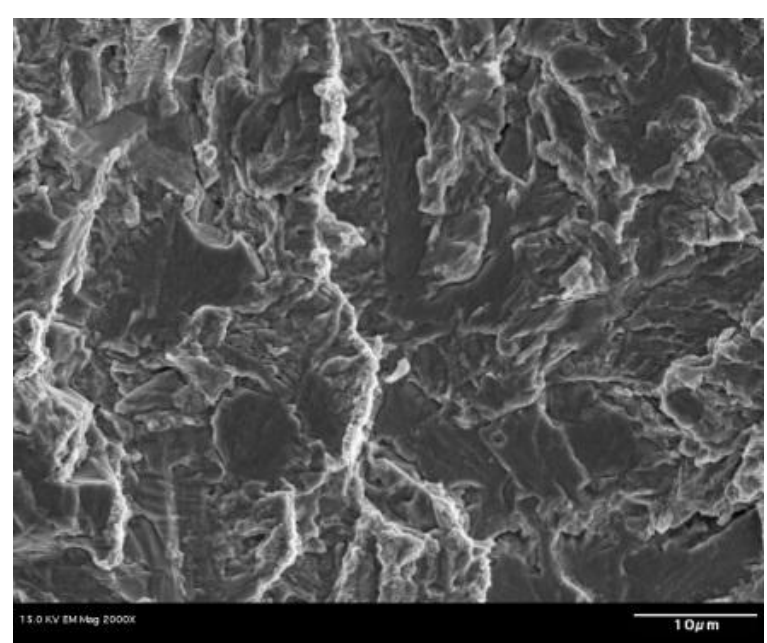

(c)

Figure $7 \quad$ Scanning electron microscope images of fracture surfaces from fatigue crack growth tests performed in $21 \mathrm{MPa}$ hydrogen gas at $\Delta \mathrm{K} \sim 8.5 \mathrm{MPa} \mathrm{m}^{1 / 2}$ : (a) base metal, (b) 15 mm off-center, (c) center of FSW. In all images, crack growth direction is from bottom to top. Arrows point to triple points, indicative of intergranular fracture. 


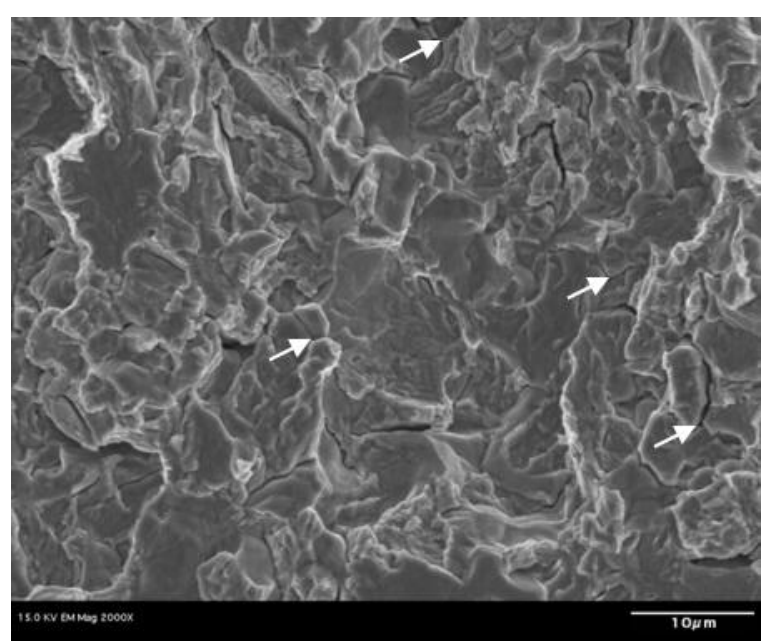

(a)

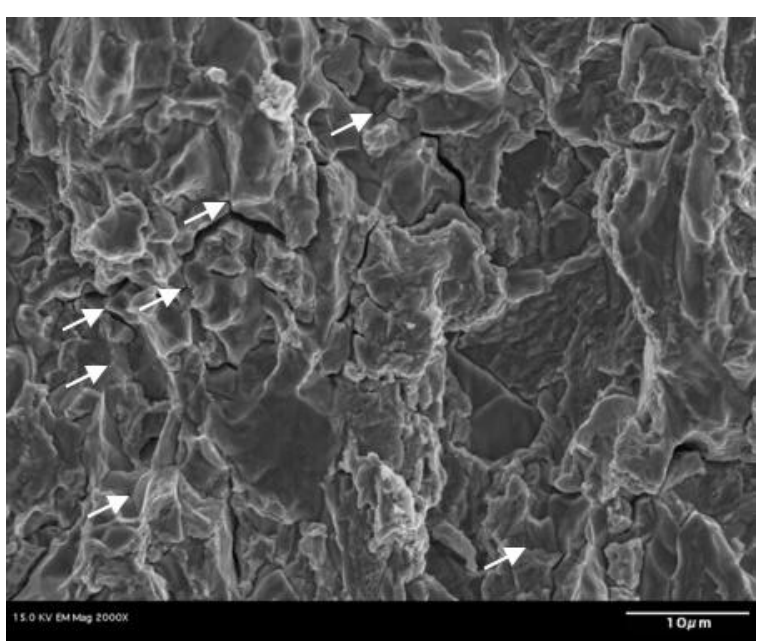

(b)

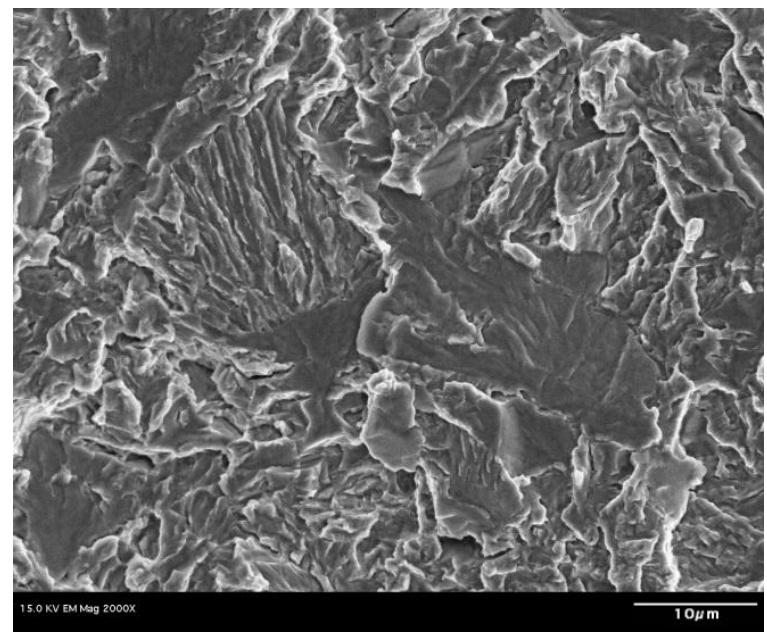

(c)

Figure $8 \quad$ Fracture surfaces of X52 pipeline steel tested in $21 \mathrm{MPa}$ hydrogen gas at locations corresponding to $\Delta \mathrm{K} \sim 10.5 \mathrm{MPa} \mathrm{m}^{1 / 2}$ : (a) BM, (b) $15 \mathrm{~mm}$ off-center, (c) FSW. In all images, crack growth direction is from bottom to top. Arrows point to triple points, indicative of intergranular fracture. 


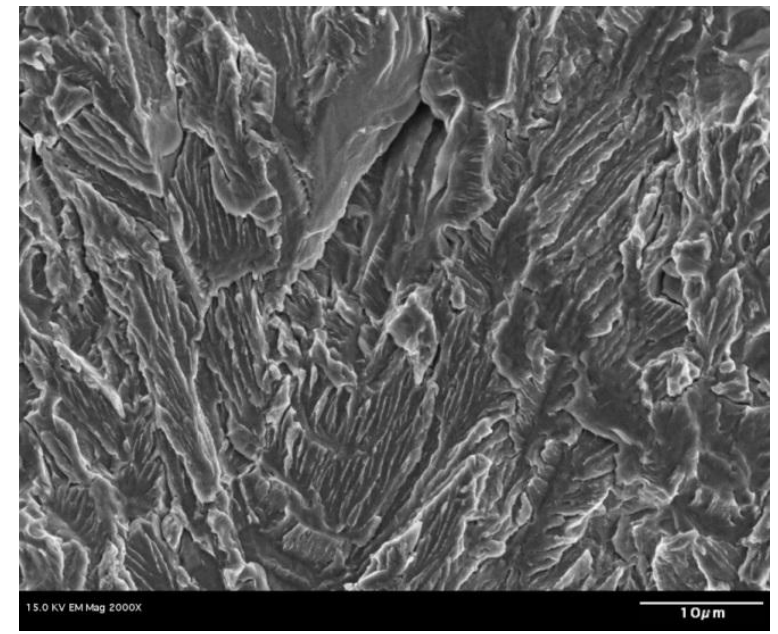

(a)

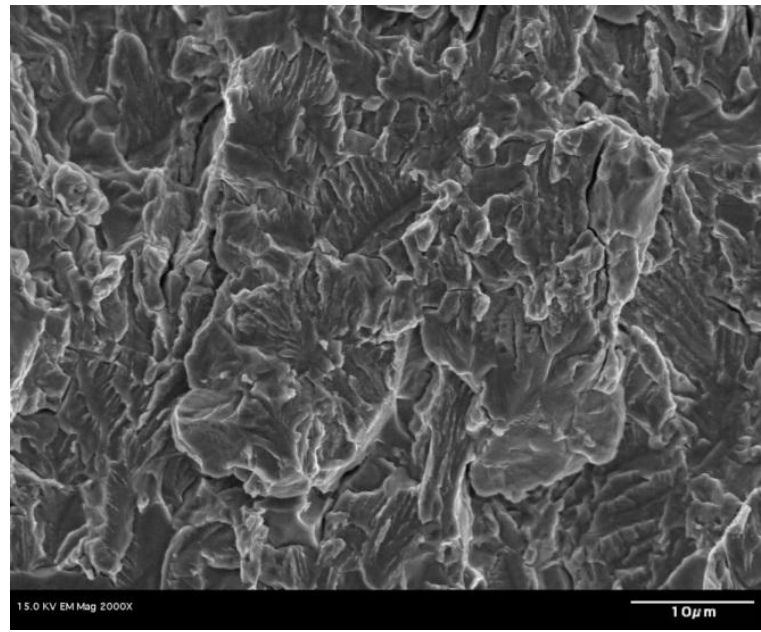

(b)

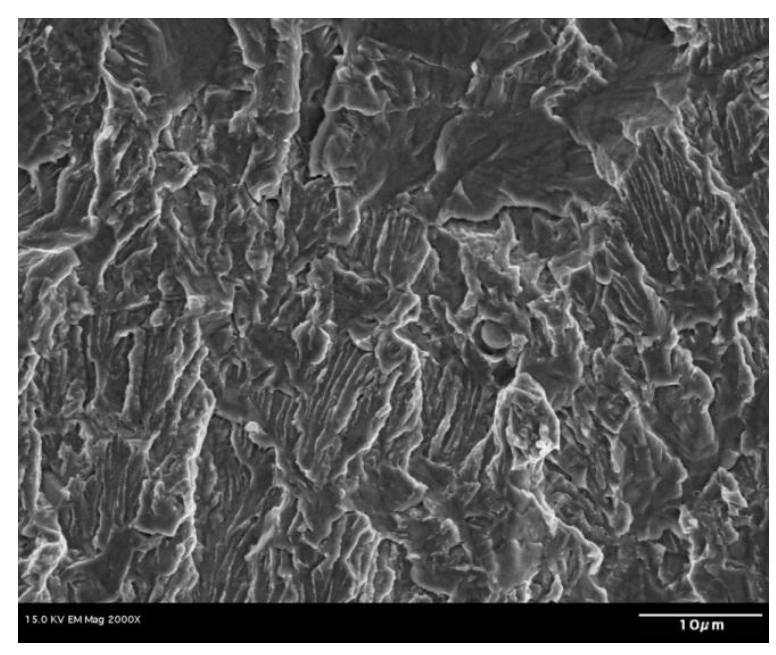

(c)

Figure 9 Fracture surfaces of X52 pipeline steel tested in $21 \mathrm{MPa}$ hydrogen gas at locations corresponding to $\Delta \mathrm{K} \sim 15 \mathrm{MPa} \mathrm{m}^{1 / 2}$ : (a) BM, (b) $15 \mathrm{~mm}$ off-center, (c) FSW. In all images, crack growth direction is from bottom to top.

\section{Discussion}

The three regions of the friction stir welded pipe examined in this study exhibit accelerated fatigue crack growth when tested in $21 \mathrm{MPa}$ hydrogen gas. Repeatability is observed among triplicate tests in each region; however, differences in FCGR are observed among the regions tested particularly in the lower $\Delta \mathrm{K}$ range (e.g. less than $15 \mathrm{MPa} \mathrm{m}^{1 / 2}$ ). The FSW region displays marginally higher FCGR at lower $\Delta \mathrm{K}$ when compared to the BM (Fig. 4). Notably, the $15 \mathrm{~mm}$ off-center region consistently exhibits lower FCGR than the BM, yet the two regions have similar microstructures (Fig. 2), hardness (Fig. 3), and fracture surface features (Figs. 7 and 8). The FSW fracture surface does not display intergranular fracture features at any of the $\Delta \mathrm{K}$ values 
examined (Figs. 7-9) yet FCGRs are slightly higher (Fig. 4). It is well documented [5, 6] that the onset of HA-FCG in pipeline steels is often accompanied by the observance of intergranular fracture features. Previous work [5] has shown the fracture surface features to consist of intergranular fracture at the locations corresponding to the $\triangle \mathrm{K}$ where $\mathrm{HA}-\mathrm{FCG}$ commences. In the current work, intergranular fracture is observed only on the BM and $15 \mathrm{~mm}$ off-center regions but notably absent in the FSW. This suggests that intergranular fracture does not always accompany the onset of hydrogen accelerated fatigue crack growth in pipeline steels. Furthermore, microstructural differences between the weld and base metal play less of a role at higher $\Delta \mathrm{K}$ ranges which is revealed by the convergence of FCGRs and similar fracture surface features. However, despite subtle differences in the fatigue crack growth relationships and fracture surfaces of the three regions of the FSW pipe, the overall characteristics of the FCGR are consistent with pipeline steels tested in high pressure hydrogen $[2-8,10]$.

Recently, FCGR data have been measured for conventional arc welded steel pipes tested in high pressure hydrogen $[8,10]$. In general, hydrogen accelerated fatigue crack growth rates of the arc welds are comparable or modestly greater than the base metal when tested in $21 \mathrm{MPa}$ hydrogen at $\mathrm{R}=0.5$ and a frequency of $1 \mathrm{~Hz}$. However, there is a noticeable lack of data in the literature for FCGR of friction stir welded steel pipes tested in high pressure hydrogen. Therefore, FCGR data for welds fabricated by conventional methods such as arc welding are referenced for comparison to the friction stir weld data measured in this study. Figure 10 shows da/dN vs $\Delta \mathrm{K}$ relationships for pipeline steel welds tested in high pressure hydrogen at a frequency of $1 \mathrm{~Hz}$ and $\mathrm{R}=0.5$. From the current study, data are shown for the X52 BM and X52 FSW in hydrogen gas at $1 \mathrm{~Hz}$, and $\mathrm{BM}$ in air at $10 \mathrm{~Hz}$. Additionally, fatigue crack growth relationships from an X65 steel pipeline gas metal arc girth weld (GMAW) [8] are plotted in Fig. 10. This X65 GMAW microstructure consists of grain boundary ferrite, Widmanstatten ferrite, ferrite with aligned second phase, and dispersed carbides [8]. In addition, FCGR data for an X52 vintage girth weld (GW) in hydrogen gas [10] are included in Fig. 10 for comparison to the FSW pipe. This X52 vintage GW was fabricated in 1964 and tested at a pressure of $34 \mathrm{MPa}$ hydrogen gas. The X52 vintage $\mathrm{GW}$ microstructure is a mixture of polygonal ferrite, acicular ferrite and dispersed carbides [10]. The X65 GMAW tested previously and the X52 FSW and X52 BM tested in the current study exhibit similar FCGRs in $21 \mathrm{MPa}$ hydrogen gas. The FCGR of the X52 vintage GW was slightly lower than rates for the X52 BM and X52 FSW. Overall, Fig. 10 shows that the X52 FSW and X52 BM exhibit FCGR relationships in hydrogen gas that are comparable to conventional arc welded pipeline steels of similar strength. This suggests that the friction stir welding process could potentially serve as a cost-effective joining method and provide comparable reliability to conventional arc-welding processes in hydrogen pipelines.

One factor that was not discussed in this paper is the effect that residual stress can have on the FCGR relationships. Residual stresses can cause shifts in the effective $\Delta \mathrm{K}$. Compressive or tensile residual stresses are additive to the applied $\Delta \mathrm{K}$ resulting in a shift in the da/dN versus $\Delta \mathrm{K}$ 
curve as was recently demonstrated and reported in [8]. However, the effects of residual stresses were not characterized for the different material regions examined in this study and therefore, the comparisons shown in Fig. 10 relate only to the applied $\Delta \mathrm{K}$. The magnitude of residual stress can vary from pipe to pipe depending on factors such as welding conditions, pipe thickness, and preheat treatment. It is also possible that the residual stresses are alleviated during the machining process which may reduce the magnitude that may have been present in the original welded pipe. Uniform crack fronts were observed in the welds tested, as shown in Fig. 5 which suggests that the magnitude of residual stress was either minimal or uniform through-thickness. In summary, the comparisons shown in Fig. 10 relate specifically to the fatigue crack growth behavior based on the response to the applied $\Delta \mathrm{K}$.

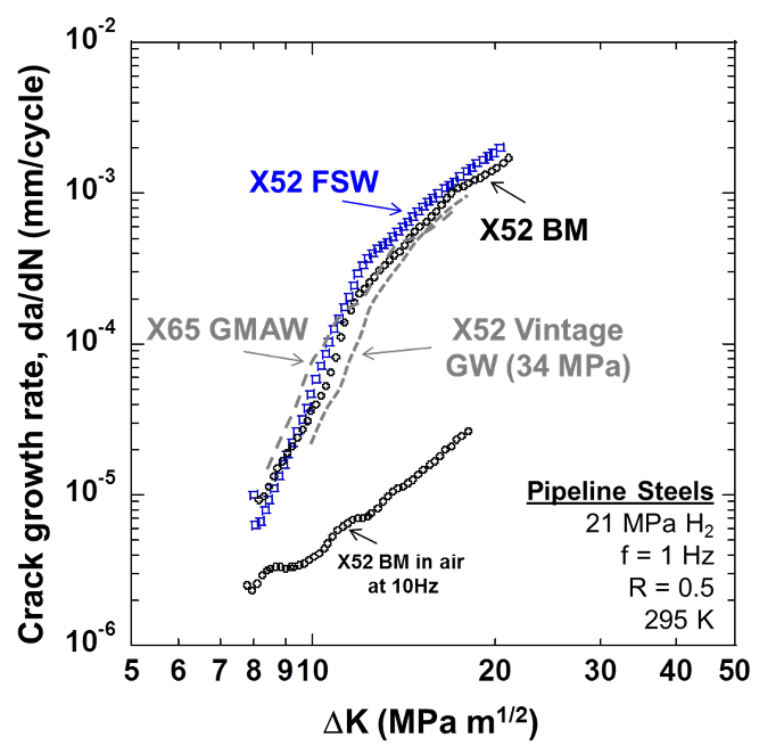

Figure 10 Fatigue crack growth relationships (da/dN vs $\Delta \mathrm{K})$ for pipeline steels tested in high pressure hydrogen gas at $1 \mathrm{~Hz}$ and $\mathrm{R}=0.5$. X52 BM and X52 FSW data in 21 MPa hydrogen gas are from the current study. X65 GMAW data (21 MPa hydrogen gas) are from [8] and X52 Vintage GW data (34 MPa hydrogen gas) are from [10]. Included are da/dN vs $\Delta \mathrm{K}$ data for $\mathrm{X} 52 \mathrm{BM}$ in air.

\section{Conclusions}

Fatigue crack growth rates (FCGR) were measured for an X52 friction stir welded pipe in 21 MPa hydrogen gas. Three regions of the pipe were tested: base metal, center of friction stir weld (FSW), and $15 \mathrm{~mm}$ off-center of the friction stir weld. Triplicate tests revealed repeatability within each region tested. Hydrogen accelerated FCGRs of the FSW were marginally greater than those in the base metal and off-center regions. Examination of the fracture surfaces revealed intergranular fracture for the BM and off-center specimens and the absence of intergranular 
fracture for the FSW specimen at lower $\Delta \mathrm{K}$ levels. Similar hydrogen accelerated fatigue crack growth was observed for FSW and conventional arc welds from similar grade pipes.

\section{Acknowledgements}

The authors would like to acknowledge the support of the Hydrogen Effects on Materials Laboratory team at Sandia National Laboratories. Metallographic samples were prepared and imaged by Andy Gardea and Ryan Nishimoto. Sandia National Laboratories is a multi-mission laboratory managed and operated by Sandia Corporation, for the U.S. Department of Energy's National Nuclear Security Administration under contract DE-AC04-94AL85000. Friction stir weld was prepared by Oak Ridge National Laboratory, managed by UT-Battle for the U.S. Department of Energy under Contract No. DE-AC05-00OR22725. This work was supported by the US Department of Energy Fuel Cell Technologies Office through the Hydrogen Delivery sub-program.

\section{References:}

[1] ASME. Hydrogen Standardization Interim Report for Tanks, Piping, and Pipelines. In STP/PT-003. 2005:220.

[2] Amaro RL, Drexler ES, Slifka AJ. Fatigue crack growth modeling of pipeline steels in high pressure gaseous hydrogen. Int J of Fatigue 2014;62:249-257.

[3] Slifka AJ, Drexler ES, Nanninga NE, Levy YS, McColskey JD, Amaro RL, Stevenson AE. Fatigue crack growth of two pipeline steels in a pressurized hydrogen environment. Corr Sci 2014;78:313-321.

[4] San Marchi C, Somerday BP, Nibur KA, Stalheim DG, Boggess T, Jansto S. Fracture and Fatigue of Commercial Grade API Pipeline Steels in Gaseous Hydrogen. In proceedings of ASME 2010 Pressure Vessels \& Piping Division, Bellevue, Washington USA, 2010.

[5] Somerday BP, Sofronis P, Nibur KA, San Marchi C, Kirchheim R. Elucidating the variables affecting accelerated fatigue crack growth of steels in hydrogen gas with low oxygen concentrations. Acta Mater 2013;61:6153-6170.

[6] Cialone HJ, Holbrook JH. Effects of gaseous hydrogen on fatigue crack growth in pipeline steel. Met Trans A 1985;16:115-122.

[7] San Marchi C, Somerday BP, Nibur KA, Stalheim DG, Boggess T, Jansto S. Fracture Resistance and Fatigue Crack Growth of X80 Pipeline Steel in Gaseous Hydrogen. 2011. In proceedings of ASME 2011 Pressure Vessles \& Piping Division, Baltimore, Maryland USA.

[8] Ronevich JA, Somerday BP. Assessing Gaseous Hydrogen Assisted Fatigue Crack Growth Susceptibility of Pipeline Steel Weld Fusion Zones and Heat Affected Zones. In 
Special Issue on Advances in Fatigue and Fracture Mechanics for Materials Performance and Characterization 2016.

[9] Moro I, Briottet L, Lemoine P, Doyen O, De Dinechin G. Fatigue Crack Growth of a CMn Steel and Associated Weld Under Hydrogen Pressure. In Proceedings of 2012 International Hydrogen Conference, Moran, WY 2012:309-317.

[10] Slifka AJ, Drexler ES, Amaro RL, Lauria DS, Hayden LE, McCowan CN, Sowards JW. Measurements of Fatigue Crack Growth Rates of the Heat-Affected Zones of Welds of Pipeline Steels. In Proceedings of ASME 2015 Pressure Vessels and Piping Conference, Boston, Massachusetts, USA. 2015.

[11] Aydin H, Nelson TW. Microstructure and mechanical properties of hard zone in friction stir welded X80 pipeline steel relative to different heat input. Mater Sci and Eng A 2013;586:313-322.

[12] Feng Z, Lim YC, Flexible Friction Stir Joining Technology: Final Technical Report, ORNL/TM-2015/339, Advanced Manufacturing Office, July 23, 2015

[13] ASTM. E647-11 Standard Test Method for Measurement of Fatigue Crack Growth Rates. 2011. ed. West Conshohocken, PA,.

[14] ASME. B31.12 Hydrogen Piping and Pipelines. 2011. New York, NY: ASME. 